\title{
A Study on the Effects of UV on Preferential Digestion of Chloroplast Nuclei in Young Zygote of Chlamydomonas reinhardtii
}

\author{
Hidenobu Uchida', Shigeyuki Kawano', Soichi Nakamura ${ }^{2}$ \\ and Tsuneyoshi Kuroiwa ${ }^{1}$ \\ ${ }^{1}$ Department of Botany, Faculty of Science, University of Tokyo, \\ Hongo, Bunkyo-ku, 113 Japan \\ 2Department of Biology, Division of General Education, University \\ of the Ryukyus, Nishiharacho, Okinawa, 902-01 Japan
}

Accepted March 22, 1992

The heterothallic isogamous green alga, Chlamydomonas reinhardtii, has been used as a model organism for the study of maternal inheritance of chloroplast genes (Sager 1954, 1981, Gillham 1974). For the last decade, high resolution epifluorescence microscopy has made it possible to study the behavior of individual chloroplast nuclei (cp-nuclei; complexes containing DNA, RNA and proteins) in each zygote. Kuroiwa et al. (1982) presented the first evidence by epifluorescence microscopy that in $C$. reihardtii the cp-nuclei from male (mating type minus, $\mathrm{mt}^{-}$) parent disappear within 40-50 min after mating, while those from female (mating type plus, $\mathrm{mt}^{+}$) parent persist. Preferential digestion of the male cp-nuclei in young zygotes has also been reported in C. moewusii (Coleman and Maguire 1983), Dictyosphaeria cavernosa and Acetabularia calyculus (Kuroiwa et al. 1985). Thus, rapid preferential digestion of cp-nuclei was suggested as the reason for the maternal inheritance of chloroplast genes (Kuroiwa et al. 1982, Kuroiwa 1985).

UV irradiation of female parent altered maternal gene transmission in C. reinhardtii, leading to an increase of paternal transmission (Sager and Ramanis 1967). Kuroiwa et al. (1983) showed cytologically that UV irradiation of female gametes before mating caused retention of the paternal cp-nuclei in zygote and irradiation of only the male parent did not affect preferential digestion. One hypothesis to explain the inhibition of the preferential digestion of cp-nuclei in $C$. reinhardtii is that UV irradiation damages the genes involved in this process. We examined the action spectrum of the inhibition of preferential digestion to identify the target of UV irradiation. We then determined the most effective period of UV irradiation of zygotes to learn when the genes involved in preferential digestion function.

\section{Materials and methods}

Wild type strains of $C$. reinhardtii, $137 \mathrm{c}, \mathrm{mt}^{+}$and $\mathrm{mt}^{-}$, were used in this experiment. Vegetative cells were grown and converted into gametes as previously described (Nakamura et al. 1986), except for the following changes: agar plate contained $3 \mathrm{~g} / \mathrm{l}$ sodium acetate and the light sources were fluorescent lamps for plant growth (Homolux PG, Matsushita Electric Industrial Co. Ltd., Osaka, Japan). Density of the $\mathrm{mt}^{+}$and $\mathrm{mt}^{-}$gametes was $5 \times 10^{\circ}$ cells/ $\mathrm{ml}$. Equal numbers of the two type of gametes were mixed to produce zygotes. Mating efficiency (Hoffman and Goodenough 1980) was determined at 10 min after mixing.

An action spectrum for the inhibition of preferential digestion was obtained for irradiation with monochromatic light of $250-300 \mathrm{~nm}$. The action spectrum had a linear dispersion of 
about $0.8 \mathrm{~nm} / \mathrm{cm}$ on a horseshoe-shaped focal curve (about $7 \mathrm{~m}$ long) of using the Okazaki Giant Spectrograph (Watanabe et al. 1982). A $30 \mathrm{~kW}$ xenon short arc lamp was used as the light source. Monochromatic light was projected for $35 \mathrm{sec}$ directly at a $20 \mu \mathrm{l}$ suspension containing one type of gamete. This suspension was mixed with a $20 \mu \mathrm{l}$ suspension of the other mating type of gamete which had not been irradiated by monochromatic light. Three hours later, the cells were fixed and stained with 4'-6-diamidino-2-phenylindole (DAPI), as previously described (Kuroiwa, 1980). The inhibition of preferential digestion of cp-nuclei from male parents in the zygotes was examined under a fluorescence microscope. The inhibition ratio was defined as the number of zygotes with intact male and female cp-nuclei divided by the total number of zygotes examined. More than 100 zygotes were observed for each data point.

To determined the UV-sensitive period for preferential digestion, zygotes were subjected to UV irradiation at various times following mixing of male and female gametes. Two hundred fifty $\mu$ l suspensions of male and female type gametes were mixed and kept under visible light (Homolux PG). The mixture was then agitated at $100 \mathrm{rpm}$ in the dark and irradiated with a UV light of $254 \mathrm{~nm}$ from a germicidal lamp (GL15, Toshiba, Kawasaki, Japan) for $1 \mathrm{~min}$ at a fluence rate of $5 \mathrm{~W} / \mathrm{m}^{2}$. The suspension was divided in half. One half was placed in the dark and the other half was placed under the visible light for $2.5 \mathrm{hr}$ after mixing. As controls for the UV irradiation study, both types of gametes were mixed and stored for $2.5 \mathrm{hr}$, either under visible light or in the dark, without being exposed to the UV pulse. Two and one-half hours after mixing, the inhibition rate of preferential digestion of cp-nuclei was scored as described above.

\section{Results}

In every experiment conducted, more than $85 \%$ of the gametes formed zygotes within $10 \mathrm{~min}$ after mixing. Fig. 1 shows fluorescent images of zygotes stained with DAPI $2.5 \mathrm{hr}$ after mixing male and female gametes. Cp-nuclei were identified as 6 small bright spots in Fig.1A, while cell nuclei were larger spheres. Fig.1A shows a zygote kept in light without UV treatment: it retained only female cp-nuclei (left half), while male cp-nuclei were digested (right half). Fig.1B shows the zygote which was exposed to a UV pulse ( $254 \mathrm{~nm}$, $1 \mathrm{~min}$ ) immediately after mixing the two gamete-types and then kept in the dark. Under these conditions, the cp-nuclei of both gametetypes remained intact. UV irradiation completely inhibited the preferential digestion.

Fig. 2 shows the action spectrum for the inhibition of preferential digestion $3 \mathrm{hr}$ after mixing both type of gametes. When the female gametes were irradiated with monochromatic light of 250-300 $\mathrm{nm}$ and mixed with male gametes which had not been irradiated, inhibition of preferential digestion of cp-nuclei from male parents was observed to be wavelengthdependent. The inhibitory effect was greatest at a wavelength of approximately $260 \mathrm{~nm}$. A wavelength ranging from 280-290 was also highly effective. On the other hand, when male gametes were exposed to this level of UV irradiation and mixed under the same conditions with female gametes which had not been irradiated, preferential digestion of male-donated cp-nuclei occurred normally (data not shown).

Fig.3A shows experimental procedure for determining the UV-sensitive period for preferential digestion of cp-nuclei from the male parent. UV light of $254 \mathrm{~nm}$ for $1 \mathrm{~min}$ at a fluence rate of $5 \mathrm{~W} / \mathrm{m}^{2}$ blocked preferential digestion almost completely without being lethal to cells, inhibiting gamete-mating, or cell nuclear fusion (Fig.1). This dosage of UV appeared to almost exclusively affect preferential digestion. Fig.3B indicates that preferential digestion in zygote stored in the dark after exposure to a UV pulse was greatly inhibited when the ex- 

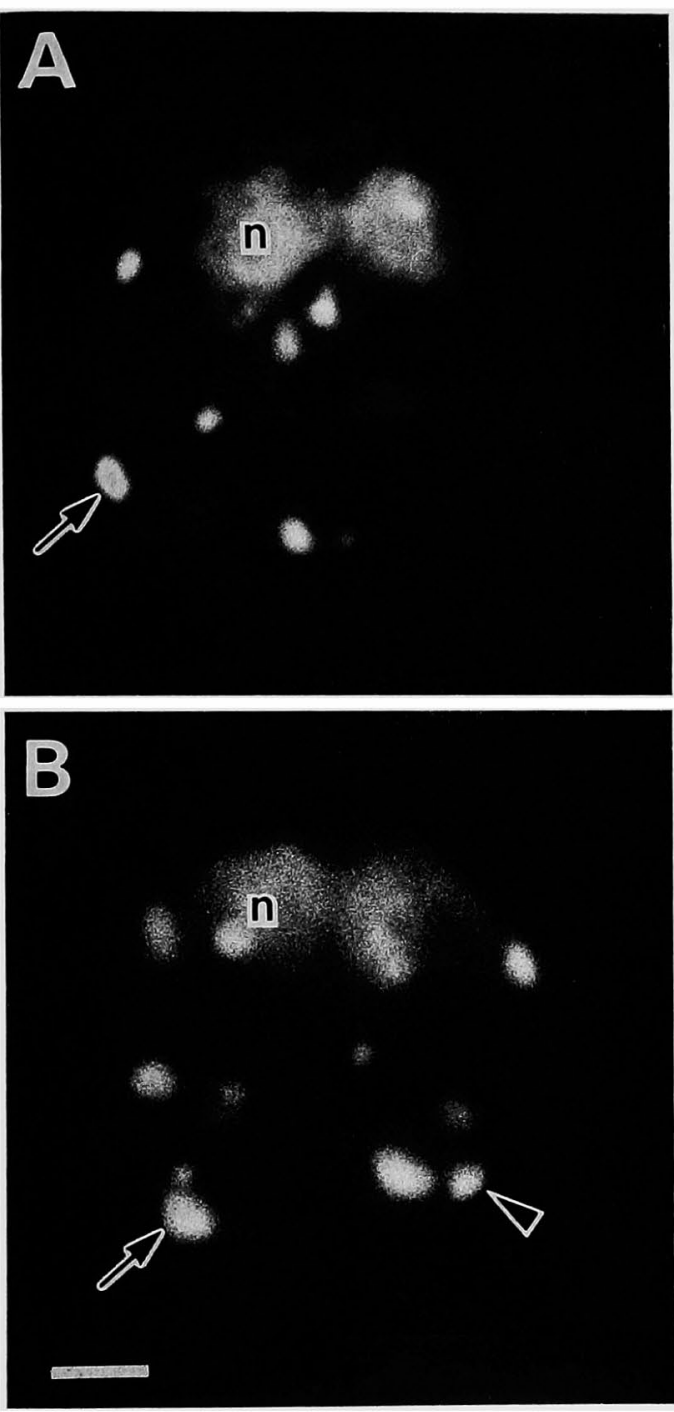

Fig. 1. Effects of UV on preferential digestion of male-donated cp-nuclei of male origin. A, a zygote kept in visible light without UV exposure. B, a zygote, which was exposed to a UV $(254 \mathrm{~nm})$ pulse immediately after mixing. These zygotes were observed by epifluorescence microscopy $2.5 \mathrm{hr}$ after mixing of the two gamete types. $\mathrm{n}=$ cell nucleus; full arrow $=c p$-nucleus of female origin; arrow head $=c p$-nucleus of male origin. Bar represents $2 \mu \mathrm{m}$.

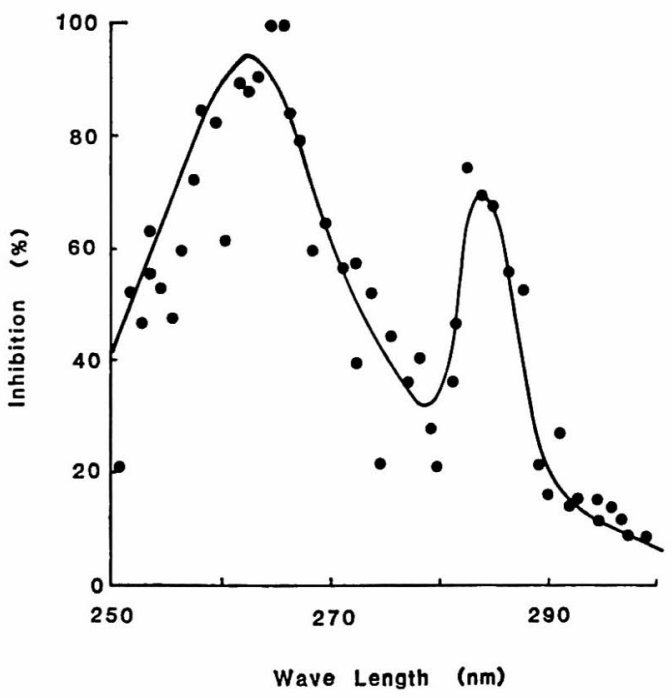

Fig. 2. Action spectrum for inhibition of preferential digestion of male-donated cp-nuclei. Female gametes were irradiated with monochromatic light and mixed with male gametes without the irradiation. The inhibition of preferential digestion of cp-nuclei from male gametes was counted by epifluorescence microscopy $3 \mathrm{hr}$ after mixing.

A

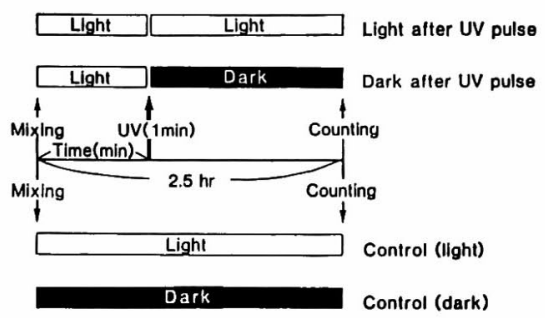

B

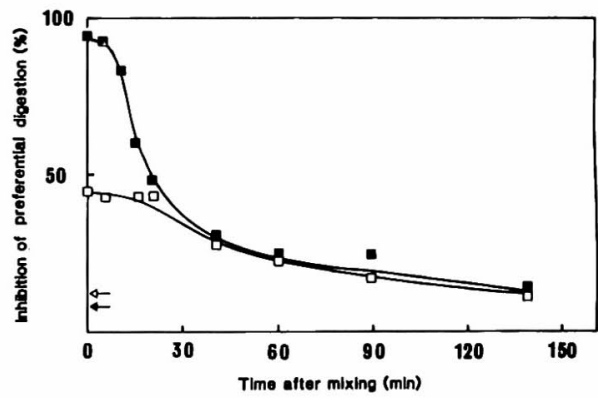

Fig. 3. Determination of UV sensitive period of preferential digestion. A, Overview of experimental procedure. B, Inhibition rate of preferential digestion versus min following mixing until exposure to UV pulse. - $\square-$ and - - - show percentages of zygotes in visible light after UV pulse and those in the dark after UV pulse, respectively. $\checkmark-$ and 4 - show control (light) and control (dark), respectively. 
posure occurred within $10 \mathrm{~min}$ after mixing the male and female gametes. This inhibition was largely overcome by subsequent incubation in visible light following the UV exposure.

\section{Discussion}

The maximum peak of inhibition for preferential digestion of cp-nuclei (Fig. 2) is similar to that of absorbance of DNA (Marmur 1961). Moreover, this inhibition was overcome by a subsequent exposure to visible light. These results show that UV irradiation damaged some portion of the nuclear DNA and inhibited preferential digestion. In prokaryotic, animal and plant cells, the principal damage to DNA due to UV is generally considered to be the formation of pyrimidine dimers. This damage is repaired by photoreactivating enzymes in the presence of visible light (Sutherland 1981). In Chlamydomonas, photoreactivation, as measured by viable cell counts, has been observed in various cell cycles (Davis 1965). In Fig. 2, a secondary maximum of inhibition was observed at a wavelength of 280-290 nm. Some proteins in the gametes may be to some extent involved in preferential digestion of cp-nuclei, since proteins have large absorbance at $280 \mathrm{~nm}$ (Warburg and Christian 1941).

Kuroiwa et al. (1983) showed that actinomycin D treatment as well as UV irradiation inhibited preferential digestion of $\mathrm{cp}$-nuclei. This indicated that expression of certain genes was necessary for preferential digestion. Nakamura et al. (1988) detected six polypeptides which were related to preferential digestion. Synthesis of these proteins occurred about 30 min after mating and was sensitive to actinomycin D and UV. These results suggest that the genes involved in preferential digestion are transcribed and translated by 30 min after mating. In our study, the high sensitivity of preferential digestion to UV exposure within the first 10 min after mixing (Fig. 3) suggests that the genes involved in preferential digestion function during this period.

\section{Summary}

Chloroplast-nuclei of male origin in the zygotes of Chlamydomonas are known to be digested after mating. This preferential digestion was inhibited by UV irradiation. An action spectrum for the inhibition of preferential digestion showed that maximum inhibition occurred between 260-265 $\mathrm{nm}$. Preferential digestion was greatly inhibited during $10 \mathrm{~min}$ after mating when the zygotes were exposed to a UV pulse $(254 \mathrm{~nm}, 1 \mathrm{~min})$. This inhibition was largely overcome by subsequent incubation in visible light. These results suggest that the genes involved in maternal inheritance function within the first 10 min after mating.

\section{Acknowledgements}

We are grateful to Dr. Masakatsu Watanabe of Giant Spectrograph, National Institute for Basic Biology, for his excellent technical assistance. We also thank Dr. Naoki Sato of Tokyo Gakugei university, for his help and advice throughout this study. This work was supported in part by a Grant-in-Aid (T. K.) for Special Research on Priority Areas (Project No. 02242102, Cellular and Molecular Basis for Reproduction Processes in Plants) from the Ministry of Education, Science and Culture, Japan.

\section{References}

Coleman, A. W. and Maguire, M. J. 1983. Cytological detection on the basis of plastid DNA in Chlamydomonas moewusii. Curr. Genet. 7: 211-218. 
Davis, D. R. 1965. Repair mechanisms and variations in UV sensitivity within the cell cycle. Mutat. Res. 2: $477-486$.

Gillham, N. W. 1974. Genetic analysis of the chloroplast and mitochondrial genomes. Ann. Rev. Genet. 8: 347-391.

Hoffman, J. L. and Goodenough, U. W. 1980. Experimental dissection of flagellar surface motility in Chlamydomonas. J. Cell Biol. 86: 656-665.

Kuroiwa, T. and Suzuki, T. 1980. An improved method for the demonstration of in situ chloroplast nuclei in higher plants. Cell Strct. Funct. 5: 195-197.

-, Kawano, S., Nishibayashi, S. and Sato, C. 1982. Epifluorescent microscopic evidence for maternal inheritance of chloroplast DNA. Nature 298: $481-483$.

-, - and Sato, C. 1983. Mechanisms of maternal inheritance. II. RNA synthesis involved in preferential destruction of chloroplast DNA of male origin. Proc. Jap. Acad. 59: 182-185.

- 1985. Mechanisms of maternal inheritance of chloroplast DNA: An active digestion hypothesis. Microbiol. Sci. 2: 267-272.

-, Enomoto, S. and Shihira-Ishikawa, I. 1985. Preferential destruction of chloroplast nucleoids in zygotes in green algae Dictyosphaeria cavernosa and Acetabularia calyculus. Experientia 41: 1178-1179.

Marmur, J. 1961. A procedure for the isolation of deoxyribonucleic acid from micro-organisms. J. Mol. Biol. 3: 208-218.

Nakamura, S., Itoh, S. and Kuroiwa, T. 1986. Behavior of chloroplast nucleus during chloroplast development in Chlamydomonas reinhardtii. Plant Cell Physiol. 27: 775-784.

-, Sato, C. and Kuroiwa, T. 1988. Polypeptides related to preferential digestion of male chloroplast nucleoids in Chlamydomonas. Plant Sci. 56: 129-136.

Sager, R. 1954. Menderian and non-Menderian inheritance of streptomycin resistance in Chlamydomonas reinhardtii. Proc. Natl. Acad. Sci. USA 40: 356-363.

- and Ramanis, Z. 1967. Biparental inheritance of nonchromosomal gene induced by ultraviolet irradiation. Proc. Natl. Acad. Sci. USA 58: 931-935.

- 1981. The application of DNA methylation studies to the analysis of chloroplast evolution. Ann: N. Y. Acad. Sci. 361: 209-218.

Sutherland, B. M. 1981. Photoreactivating enzymes. Enzymes 14: 481-515.

Wargburg, O. and Christian, W. 1941. Isolierung und kristallisation des garungs ferments enolase. Biochem. Z. 310: 384-421.

Watanabe, M., Furuya, M., Miyoshi, Y., Inoue, Y., Iwahashi, I. and Matsumoto, K. 1982. Design and performance of the Okazaki large spectrograph for photobiological research. Photochem. Photobiol. 36: $491-498$. 